\title{
Association of the rs10830963 Polymorphism in MTNR1B with Fasting Glucose Levels in Chinese Children and Adolescents
}

\author{
Jie-Yun Song ${ }^{\mathrm{a}, \mathrm{b}^{*}}$ Hai-Jun Wang ${ }^{\mathrm{a}^{*}}$ Jun $\mathrm{Ma}^{\mathrm{c}}$ Zhi-Yuan Xu $\mathrm{Xu}^{\mathrm{a}, \mathrm{b}}$ Anke Hinney \\ Johannes Hebebrand ${ }^{d}$ Yan Wang ${ }^{\mathrm{a}}$ \\ a Division of Maternal and Child Health, School of Public Health, Peking University Health Science Center, \\ ${ }^{\mathrm{b}}$ Key Laboratory of Epidemiology, Ministry of Education, \\ ${ }^{\prime}$ Institute of Child and Adolescent Health, Peking University, Beijing, China \\ ${ }^{\mathrm{d}}$ Department of Child and Adolescent Psychiatry, University of Duisburg-Essen, Essen, Germany
}

\section{Keywords}

MTNR1B $\cdot$ Glucose $\cdot$ Children · Adolescents

\section{Summary}

Aims: We aimed to identify whether the risk G-allele was associated with fasting glucose level and other pre-diabetic and obesity-related phenotypes in Chinese children and adolescents. Methods: The rs10830963 polymorphism in MTNR1B was genotyped in 2,030 Chinese children and adolescents of two independent studies. Association with fasting glucose levels and risk of impaired fasting glucose (IFG) were initially tested. Subsequently we analyzed the association with fasting insulin, homeostasis model assessment for insulin resistance (HOMAIR) and for beta cell function (HOMA-B), the quantitative insulin sensitivity check index (QUICK) and obesity-related phenotypes (BMI standard deviation score, waist circumference etc.). Results: The G-allele of rs10830963 was associated with increased fasting glucose level in Chinese children and adolescents (increase of 0.072 $\mathrm{mmol} / \mathrm{l}$ per G-allele, 95\% Cl 0.034-0.111, $\mathrm{p}=2.46 \times 10^{-4}$ ). The $\mathrm{G}$-allele was also associated with an increased risk of IFG (OR $=1.21,95 \% \mathrm{Cl} 1.00-1.46$, nominal $p=0.048$ ). We found the glucose-raising G-allele was nominally associated with reduced HOMA-B. No association to other pre-diabetic or obesity-related phenotypes was detected. Conclusions: The rs10830963 polymorphism in MTNR1B was associated with increased fasting glucose and risk of IFG in Chinese children and adolescents. The effect may result from reduced pancreatic beta cell function, but the mechanism awaits further studies.

\footnotetext{
*Both authors contributed equally to this paper.
}

\section{KARGER}

Fax +497614520714

Information@Karger.de

www.karger.com

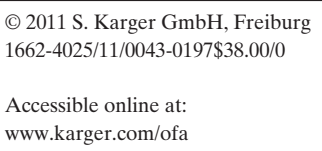

\section{Introduction}

Melatonin was recently inferred to play an important role in the development of type 2 diabetes by influencing insulin secretion and endogenous glucose production [1]. The effect of melatonin is mediated by the membrane receptors, including melatonin receptor 1 (MT1, encoded by $M T N R 1 A$ ) and melatonin receptor 2 (MT2, encoded by MTNR1B). MTNR1B was found to be expressed in human retina, diencephalon, pancreatic islets and beta cells [2].

Among the variants identified to be associated with higher fasting glucose levels or the increased risk of type 2 diabetes by genomewide association studies, common genetic variants within $M T N R 1 B$ were associated with both phenotypes [2,3]. The variant with the strongest association signal was the single nucleotide polymorphism (SNP) rs10830963, located in the single intron $(11.5 \mathrm{~kb})$ of MTNR1B. A meta-analysis revealed that rs10830963 is strongly associated with fasting glucose levels and moderately associated with an increased risk to develop diabetes [3]. The association with fasting glucose levels was replicated in several studies based on European populations [2, 4-9]. A study in non-diabetic individuals has identified an association of rs10830963 with impaired glucosestimulated insulin secretion [4]. The risk allele was also related to impairment of early insulin secretion and beta cell dysfunction that might represent the pathomechanism for the increased risk of type 2 diabetes by the rs10830963 risk allele $[3,7]$. Recently, the associations of rs 10830963 with the elevated fasting glucose and risk of type 2 diabetes were reported in Asian adults, including Chinese [10-15], Japanese and Sri Lankan populations [16]. 
Concomitant with the obesity epidemic, the prevalence of type 2 diabetes in young individuals has raised worldwide [17]. Most studies of fasting glucose or type 2 diabetes focused on adults while there were limited studies among children and adolescents. Up to date, rs10830963 was reported to influence fasting glucose levels of children in some European studies $[5,9]$. But there was only one related study in Chinese adolescents recently published during the review of our paper [12]. Whether the glucose-raising allele has similar effects in Asian children and adolescents need more studies. Therefore, we studied associations of rs10830963 with the pre-diabetic and obesityrelated phenotypes in two independent study groups, including 2,030 Chinese children and adolescents aged 7-18 years.

\section{Subjects and Methods}

\section{Subjects}

We conducted an association study in two independent study groups recruited from the urban regions of Beijing, China. The first study group, including 386 obese, 400 overweight and 151 normal-weight individuals, came from the study on Adolescent Lipids, Insulin Resistance and Candidate Genes (ALIR) in nine middle schools of Dongcheng District of Beijing. The second study group, including 319 obese, 318 overweight and 456 normal-weight individuals, was from the Comprehensive Prevention Project for Overweight and Obese Adolescents (CPOOA) with physical exercise and healthy nutrition as instruments in five elementary and middle schools of the Haidian District of Beijing. The ascertainment strategies for the two study groups have been described in detail previously $[18,19]$. We used the BMI percentile criteria for obese, overweight and normal-weight children and adolescents, which were determined in a representative Chinese population [20]. According to the criteria, the children and adolescents with an age- and gender-specific BMI greater or equal to the 95th percentile are defined as obese, while those with a BMI between 85th and 95th percentile are overweight and those with a BMI between 15th and 85th percentiles are normal weight. Individuals with any cardiovascular or metabolic disease were excluded. The two studies were approved by the ethic committee of Peking University Health Science Center. Written informed consent was provided by all participants and, in the case of minors, their parents. The general characteristics of the study groups are shown in table 1.

Anthropometric measurements, including height, weight, waist and hip circumferences, were determined according to standard protocols $[18,19]$. Mean systolic and diastolic blood pressures were calculated by averaging three measurements. The skin fold thickness on the triceps, subscapula, abdomen and suprailium was measured. Fasting venous blood samples were taken for measurement of total cholesterol, triglyceride, lowdensity lipoprotein cholesterol, high-density lipoprotein cholesterol and fasting glucose using a biochemical auto-analyzer (Hitachi 7060, Tokyo, Japan). Fasting insulin was determined by the radio-immunoassay method (Beijing North Institute of Biological Technology, Beijing, China). We calculated the homeostasis model assessment of insulin resistance (HOMAIR) and the homeostasis model assessment of pancreatic beta cell function (HOMA-B), by using the HOMA Calculator version 2.2 available from the Oxford Centre for Diabetes, Endocrinology and Metabolism (www. dtu.ox.ac.uk, accessed in March 2010) [21]. The quantitative insulin sensitivity check index (QUICK) was calculated according to the formula: QUICK $=1 / \log ($ fasting insulin $(\mu \mathrm{U} / \mathrm{ml}))+\log ($ fasting glucose $(\mathrm{mmol} / \mathrm{l}))$ [21]. The sex- and age-specific BMI standard deviation score (BMI-SDS) was calculated by using the growth reference data of the World Health Organization for children and adolescents aged 5-19 years [22].

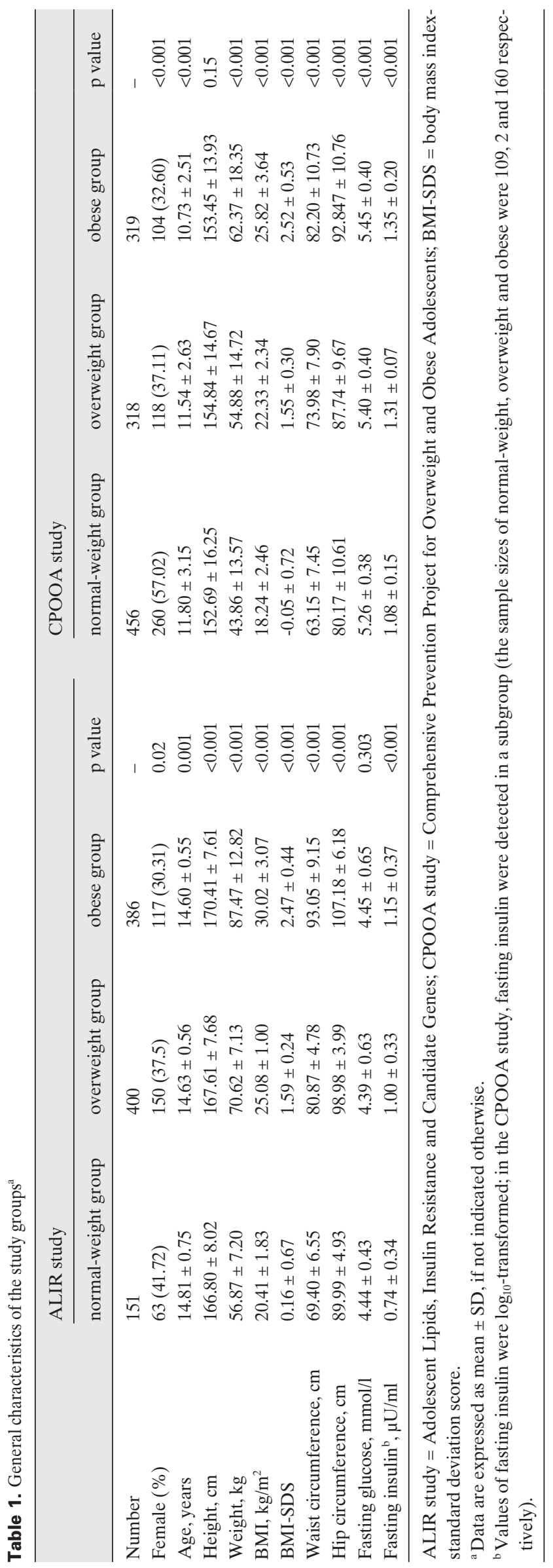




\section{Genotyping}

Genomic DNA was extracted from blood leukocytes by the phenol/chloroform extraction method. Genotyping of rs10830963 was carried out with tetra-primer amplification refractory mutation system analysis (tetra-primer ARMS-PCR) [23]. The sequences of primers were: $F_{\text {out }}: 5$ '-

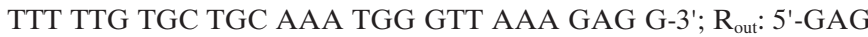
CCT TTG TTC AGA ACC ATG CTG CTT A-3'; Fin: 5'-CCA GTG

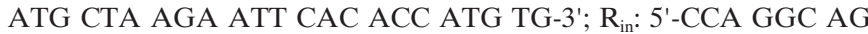
TTA CTG GTT CTG GAT TGG-3' (product size: G-allele (439 bp, 220 bp), C-allele (439 bp, 274 bp)). Different PCR products were clearly distinguished on $2.5 \%$ agarose gels stained with ethidium bromide. For reference ARMS-PCR of individuals with genotypes identified by sequencing were included in every run. For validity of genotypes, allele assignments were made by at least two experienced individuals independently. Discrepancies were solved unambiguously either by reaching consensus or by repeating. We genotyped $5 \%$ of samples twice for quality control and the genotyping concordance rate was $100 \%$.

\section{Statistics}

The genotype data of the normal-weight group was tested for deviation from Hardy-Weinberg equilibrium with the $\chi^{2}$ test. The relationships between rs10830963 polymorphism and quantitative variables (fasting glucose, fasting insulin, HOMA-B etc.) were tested by using the linear regression analysis with age, sex and study population as covariates. The values of fasting insulin, HOMA-B and HOMA-IR were $\log _{10}$-transformed to address the skewness of distributions. Sensitivity analysis adjusting for BMI was also performed. Logistic regression analysis adjusted for age, gender and study population was used to calculate the odd ratio (OR) of the G-allele carriers for impaired fasting glucose levels. Additionally we used the linear regression analysis to compare the levels of obesity-related phenotypes of G-allele carriers with that of the noncarriers. All analyses were performed under an additive genetic model with the rs10830963 G-allele as the risk allele. For all variables, estimates and $95 \%$ confidence intervals (95\% CIs) were calculated. Unless otherwise stated, all reported $\mathrm{p}$ values are nominal, two-sided and not adjusted for multiple testing. SPSS 10.0 software was used for the above statistical analyses (SPSS, Chicago, IL, USA). Revman 5.0 software (www.cc-ims. net/revman) was used to calculate standardized mean difference (SMD) of fasting glucose between different genotypes.

\section{Results}

The phenotypic characteristics of our study groups were shown in table 1 . The age and gender differed by the obese subgroups in the two independent studies $(\mathrm{p}<0.05)$. Weight, BMI, BMI-SDS, waist circumference, hip circumference and fasting insulin were significantly higher in overweight and obese groups than in their counterparts with normal weight $(\mathrm{p}<0.001)$. The fasting glucose is significantly different by the obese subgroups in the CPOOA study $(\mathrm{p}<0.001)$, but not in the ALIR study $(\mathrm{p}=0.303)$.

We analyzed the rs10830963 genotype and phenotype data of 2,030 Chinese children and adolescents from two independent studies (ALIR and CPOOA). No deviation from HardyWeinberg equilibrium was observed in the normal-weight individuals of each study ( $p=0.724$ in ALIR and $p=0.984$ in CPOOA). In total, 373 (18.37\%) children and adolescents were homozygous carriers of the G-allele, 986 (48.57\%) were heterozygous, and $671(33.05 \%)$ were homozygous carriers of the $\mathrm{C}$-allele. The $\mathrm{G}$-allele frequency was $42.66 \%$.
Applying an additive genetic model, we found a significant association between the rs10830963 G-allele and increased fasting glucose levels in both ALIR and CPOOA with the linear regression analysis adjusted for age and gender (both $\mathrm{p}<0.001$; table 2$)$. We performed a combined analysis and confirmed the association $\left(\mathrm{p}=2.64 \times 10^{-4}\right.$; table 3$)$. The effect size of the G-allele on fasting glucose was $0.072 \mathrm{mmol} / 1(95 \%$ CI 0.034-0.111 mmol/l; table 3). The effect size did not change in the further analysis adjusted for BMI $(\beta=0.076 \mathrm{mmol} / \mathrm{l}$, 95\% CI 0.045-0.107 mmol/1; $\left.\mathrm{p}=1.97 \times 10^{-6}\right)$.

In addition, we tested whether there was a dominant effect of rs10830963 in our study population. The SMD of fasting glucose was 0.16 (95\% CI 0.06-0.25) and 0.29 (95\% CI 0.160.42 ) for $\mathrm{CG}$ versus $\mathrm{CC}$ and $\mathrm{GG}$ versus $\mathrm{CC}$, respectively, confirming the additive effect of rs10830963.

The G-allele was also nominally associated with decreased HOMA-B levels (pancreatic beta cell function index) in the ALIR study group $(p=0.037)$ while there was no association to be observed in the CPOOA study group ( $p=0.490$; table 2$)$. In the combined analysis, we found a nominally significant association of the G-allele with decreased HOMA-B ( $p=$ 0.039 ; table 3). The effect size of rs $10839063 \mathrm{G}$-allele on fasting glucose decreased $(0.068 \mathrm{mmol} / \mathrm{l}, 95 \%$ CI $0.024-0.112$ $\mathrm{mmol} / \mathrm{l} ; \mathrm{p}=0.003$ ) in the further analysis adjusted for HOMA-B. There was no association of the rs10830963 polymorphism with fasting insulin levels, HOMA-IR, or QUICK ( $p>0.40)$.

According to the reference [24], we classified the children and adolescents into the group with impaired fasting glucose (IFG; fasting glucose being 5.6-6.9 $\mathrm{mmol} / \mathrm{l}$ ) and the normalglucose group (fasting glucose $<5.6 \mathrm{mmol} / \mathrm{l}$ ). In the combined analysis of the two independent studies, the frequency of the rs10830963 G-allele was higher in the IFG group than in the normal-glucose group (OR $=1.21,95 \%$ CI 1.00-1.46, nominal $\mathrm{p}=0.048$; table 4$)$.

The relationship between the rs10830963 and obesityrelated phenotypes was also studied in the Chinese children and adolescents. The rs10830963 genotype frequencies of the overweight or obese group were not different from that of the normal-weight group $(\mathrm{p}=0.993)$. We detected no significant association ( $\mathrm{p}>0.30$; data not shown) for BMI, BMI-SDS, waist circumference, hip circumference, total cholesterol, triglyceride, low-density lipoprotein cholesterol, high-density lipoprotein cholesterol, systolic and diastolic blood pressure as well as the skin fold thickness on triceps, subscapula, abdomen and suprailium.

\section{Discussion}

The common genetic variant rs10830963 in MTNR1B was reported to be associated with increased fasting glucose levels in several populations [5, 9]. We found a significant association of the G-allele of rs10830963 in MTNR1B with fasting glucose levels using an additive model, with the effect size of 0.076 


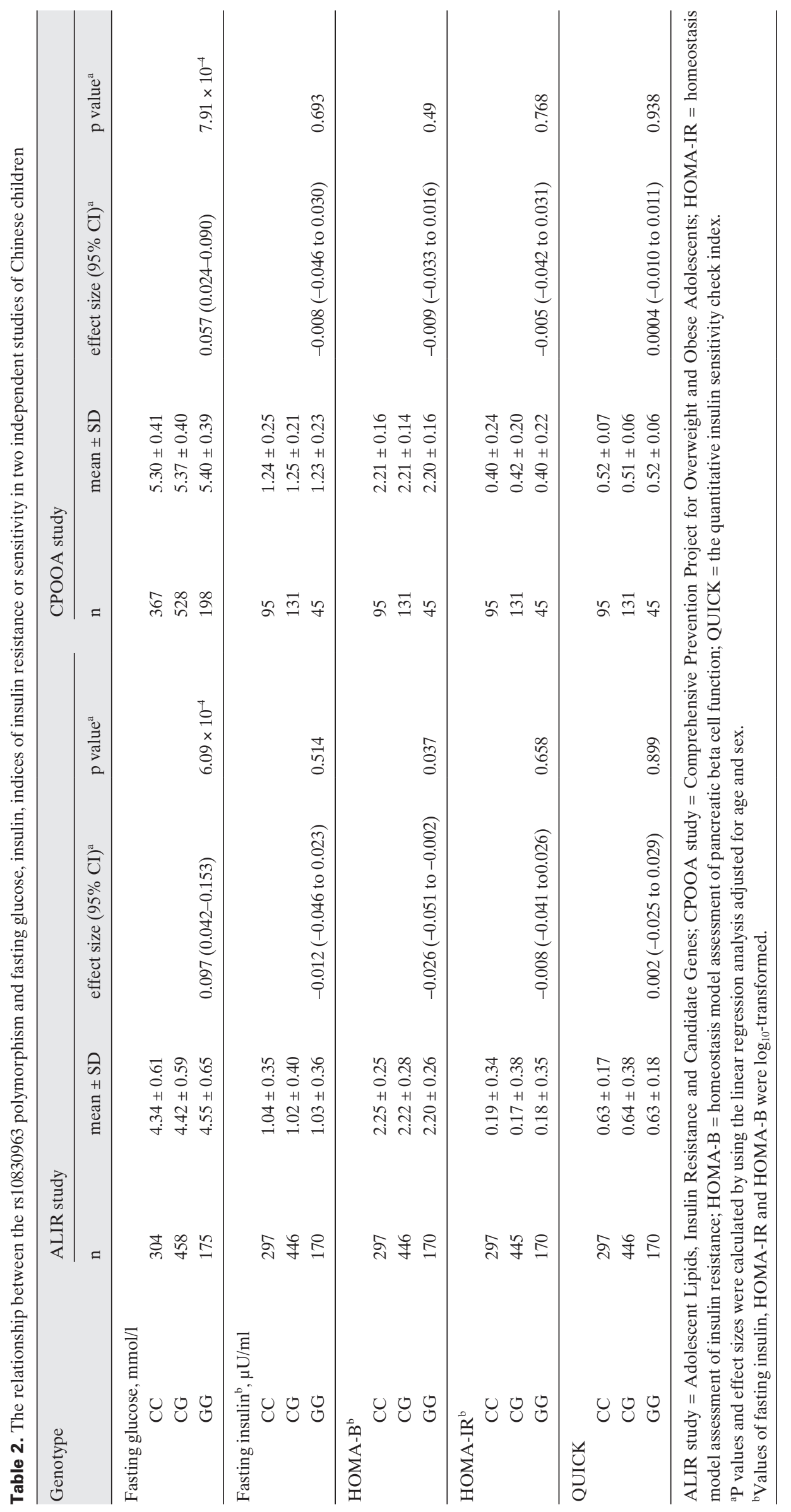


Table 3. The relationship between the rs10830963 polymorphism and fasting glucose, fasting insulin, indices of insulin resistance or sensitivity in the combined analyses of 2,030 Chinese children

\begin{tabular}{|c|c|c|c|c|}
\hline Genotype & $\mathrm{N}$ & Mean \pm SD & Effect size $^{\mathrm{a}}(95 \% \mathrm{CI})$ & $\mathrm{P}$ value ${ }^{\mathrm{a}}$ \\
\hline \multicolumn{5}{|c|}{ Fasting glucose, $\mathrm{mmol} / \mathrm{l}$} \\
\hline $\mathrm{CC}$ & 671 & $4.87 \pm 0.70$ & & \\
\hline $\mathrm{CG}$ & 986 & $4.93 \pm 0.69$ & & \\
\hline GG & 373 & $5.00 \pm 0.68$ & $0.072(0.034-0.111)$ & $2.64 \times 10^{-4}$ \\
\hline \multicolumn{5}{|c|}{ Fasting insulin ${ }^{\mathrm{b}}, \mu \mathrm{U} / \mathrm{ml}$} \\
\hline $\mathrm{CC}$ & 392 & $1.09 \pm 0.34$ & & \\
\hline CG & 577 & $1.07 \pm 0.37$ & & \\
\hline GG & 215 & $1.07 \pm 0.35$ & $-0.008(-0.036$ to 0.020$)$ & 0.581 \\
\hline \multicolumn{5}{|l|}{ HOMA-B ${ }^{b}$} \\
\hline $\mathrm{CC}$ & 392 & $2.24 \pm 0.23$ & & \\
\hline CG & 576 & $2.22 \pm 0.25$ & & \\
\hline GG & 215 & $2.20 \pm 0.24$ & $-0.021(-0.041$ to -0.001$)$ & 0.039 \\
\hline \multicolumn{5}{|l|}{ HOMA-IR ${ }^{b}$} \\
\hline $\mathrm{CC}$ & 392 & $0.24 \pm 0.35$ & & \\
\hline CG & 577 & $0.23 \pm 0.36$ & & \\
\hline GG & 215 & $0.23 \pm 0.34$ & $-0.004(-0.032$ to 0.023$)$ & 0.75 \\
\hline \multicolumn{5}{|l|}{ QUICK } \\
\hline $\mathrm{CC}$ & 392 & $0.60 \pm 0.16$ & & \\
\hline $\mathrm{CG}$ & 577 & $0.61 \pm 0.34$ & & \\
\hline GG & 215 & $0.61 \pm 0.17$ & 0.001 (-0.020 to 0.022$)$ & 0.956 \\
\hline \multicolumn{5}{|c|}{$\begin{array}{l}\text { HOMA-IR = Homeostasis model assessment of insulin resistance; HOMA-B = homeostasis model } \\
\text { assessment of pancreatic beta cell function; QUICK = the quantitative insulin sensitivity check } \\
\text { index. } \\
\text { a } \mathrm{P} \text { values and effect sizes were calculated by using the linear regression analysis adjusted for age, } \\
\text { sex and study population. } \\
{ }^{b} \text { Values of fasting insulin, HOMA-IR and HOMA-B were } \log _{10} \text {-transformed. }\end{array}$} \\
\hline
\end{tabular}

Table 4. The association of the rs10830963 polymorphism with impaired fasting glucose in the combined analysis of 2,030 Chinese children

\begin{tabular}{llllll}
\hline & \multicolumn{2}{l}{ Genotype, $\mathrm{n}(\%)$} & ${\text { Adjusted OR (95\% CI })^{\mathrm{a}}}^{*}$ P value $^{\mathrm{a}}$ \\
\cline { 2 - 4 } & $\mathrm{CC}$ & $\mathrm{CG}$ & $\mathrm{GG}$ & \\
\hline Normal glucose group & $583(33.5)$ & $849(48.7)$ & $310(17.8)$ & Reference & \\
Impaired fasting glucose group & $88(30.6)$ & $137(47.6)$ & $63(21.9)$ & $1.21(1.00-1.46)$ & 0.048 \\
\hline
\end{tabular}

${ }^{a}$ Odds ratio (OR) with $95 \%$ CI and p value were estimated with logistic regression analysis adjusted for age, sex and study population. $\mathrm{mmol} / \mathrm{l}$ per G-allele. The result was consistent with previous studies on European children and adolescents [5, 9]. Kelliny et al. [5] observed that the G-allele of rs10830963 was positively associated with fasting glucose levels $(\beta=0.069 \mathrm{mmol} / \mathrm{l})$ in 2,025 healthy children and adolescents from the European Youth Heart Study (EYHS) in Estonia and Denmark (age range 9-11 and 14-16 years). Sparso et al. [9] replicated the effect in 5,258 children aged 16 years of the Northern Finland 1986 Birth Cohort (NFBC86), with the increase of fasting glucose being $0.060 \mathrm{mmol} / \mathrm{l}$ per $\mathrm{G}$-allele.

We additionally found that the association between rs10830963 G-allele and fasting glucose levels was unaltered after adjustment for BMI, which is in line with the previous studies $[3,5]$. Our data indicated that the genetic variant contributed to elevated fasting glucose levels independently of the degree of adiposity as it had been shown in European populations $[3,5]$. The effect sizes in children of different ethnic background were similar. However, we observed that the G-allele frequency in Chinese children and adolescents was $43 \%$, which is similar to Chinese adults (42\%), but higher than the frequency in European populations (20-34\% [3]). As more Chinese people carry the risk allele of rs10830963, it was suggested that its effect on fasting glucose levels should be paid more attention in Asia.

There was a study in Chinese adolescents recently published during the review of our paper (abbreviated as PMID 
20628598) [12]. Our study not only replicated its findings but also provided more interesting findings:

i) The association of rs10830963 and fasting glucose was more significant in our study with $\mathrm{p}=2.64 \times 10^{-4}$ compared to $\mathrm{p}=0.0475$ in PMID 20628598. The reason might be that our study involved two independent cohorts from north China, having larger sample size (2,030 in our study, 1,061 adolescents in PMID 20628598).

ii) Our study population was different from PMID 20628598, including wider age range (children and adolescent aged 7-18 years in our study, adolescents with mean age $15.4 \pm$ 1.9 years in PMID 20628598), and different BMI levels $\left(23.8 \pm 4.8 \mathrm{~kg} / \mathrm{m}^{2}\right.$ in our study, $19.9 \pm 3.5 \mathrm{~kg} / \mathrm{m}^{2}$ in PMID 20628598). The results of our study will provide more evidences for the role of rs10830963.

iii) In the PMID 20628598 study, weaker and dominance effects of rs10830963 were found in Chinese, with SMD of fasting glucose being 0.20 (95\% CI $0.11-0.28$ ) and 0.23 (95\% CI 0.12-0.34) for CG versus CC and GG versus CC, respectively, which was different from the additive effect in Europeans. We performed a similar analysis in our study population, but did not find any dominant effect. In a recent meta-analysis, the overall effect size on fasting glucose among Asians tended to be smaller than that in white Europeans, but the heterogeneity observed in white Europeans may introduce bias [11]. Whether there is ethnic difference for the role of rs10830963 awaits more studies.

Moreover, we found the association of the G-allele at rs10830963 with increased risk of IFG in children and adolescents which confirmed a recent study in middle-aged Danes [9]. Girls of Caucasian and African decent aged 9-10 years with IFG were shown to be at a greater risk to develop type 2 diabetes a decade later [25]. In a study of Israelian young men, higher fasting glucose levels within the normal glycemic range were an independent risk factor for type 2 diabetes [26]. Therefore, the identification of fasting glucose gene variants in children and adolescents will be useful for screening of glucose disorder and preventing diabetes at an early age.

We also found that the G-allele of rs10830963 that leads to increased glucose level was associated with reduced pancreatic beta cell function (HOMA-B) in the ALIR study and the combined analysis. But the polymorphism had no significant effect on fasting insulin, insulin resistance (HOMA-IR) or insulin sensitivity (QUICK). The effect size of rs10839063 G-allele on fasting glucose decreased in the further analysis adjusted for HOMA-B. If our observed association between rs10830963 and HOMA-B is replicated in multiple cohorts, it might be possible that the increase in fasting glucose levels by the $\mathrm{G}$ risk allele of rs10830963 might be due to impaired pancreatic beta cell function. Some previous studies reported that the G-allele of rs10830963 was associated with decreased insulin release response to oral and intravenous glucose challenge, reduced glucose-stimulated early phase insulin secretion and decreased beta cell glucose sensitivity [4, 6, 7]. Langenberg et al. [6] further recognized that the defect of pancreatic beta cell function remained significant after accounting for the whole-body insulin sensitivity level during oral glucose tolerance test. Since the MTNR1B gene is predominantly expressed in pancreatic beta cells, the direct regulation of beta cell function was supposed to be an important pathway for the increased fasting glucose effect of rs10830963. However, the role of the polymorphism in the etiology of type 2 diabetes was not clear. Being located in the single intron of MTNR1B, the rs10830963 may not disrupt consensus transcription factor binding or cryptic alternative splice sites [3]. But the level of MTNRIB mRNA in pancreatic islets was observed to be higher in the G-allele carriers than that in the non-carriers among non-diabetics older than 45 years [7]. How the rs10830963 influences the expression of MTNR1B awaits further functional studies.

No association between the G-allele of rs10830963 and reduced HOMA-B was observed in the CPOOA study, partly due to the small size of the fasting insulin subgroup. It was also reported that the effect of the G-allele on HOMA-B is marginally stronger at a later pubertal stage than at an earlier stage [5]. In the PMID 20628598 study [12], rs10830963 was found to be associated with HOMA-B ( $\mathrm{p}=0.0042)$ in adolescents $(15.4 \pm 1.9$ years $)$. In our study the association was observed in the ALIR study, but not in the CPOOA study. We considered that the age range of the children and adolescents in the CPOOA study (7-18 years) was wider than that in the ALIR study (14-17 years), which may also have contributed to the non-significant association of rs10830963 polymorphism with HOMA-B. It was reported that the effect of the G-allele on HOMA-B is marginally stronger at a later pubertal stage than at an earlier stage [5]. The HOMA-B result of our study was interesting when it was considered together with that of the PMID 20628598 study, suggesting that the role of rs10830963 might vary in different pubertal stages. In addition, we extended the association study of rs10830963 to BMI, BMI-SDS as well as other obesity-related phenotypes. However, associations were not detected. Staiger et al. [4] had similar results for BMI, body fat content and waist circumference. Since fasting glucose was associated with BMI in the CPOOA study, the SNP was not associated with BMI making it less likely for BMI to be confounding the association between the SNP and fasting glucose. However, further studies in larger populations are necessary to clarify the role of rs10830963 in the development of obesity.

In conclusion, we found the G-allele at rs10830963 in $M T N R 1 B$ was associated with increased fasting glucose, the risk of IFG and decreased HOMA-B in Chinese children and adolescents. The polymorphism might affect pancreatic beta cell function so as to reduce insulin secretion, resulting in mpaired fasting glucose, but the mechanism awaits further studies. 


\section{Acknowledgements}

The study was supported by grants from National Natural Science Foundation of China (30700668), Specialized Research Fund for the Doctoral Program of Higher Education of China (20070001811) and the National Basic Research Program of China (973 program) (2006CB503900) and by grants from the German Bundesministerium für Bildung und Forschung
(01GS0903; NGFNplus 01GS0820). We thank all the children and adolescents and their parents for their participation.

\section{Disclosure Statement}

The authors declared no conflict of interest.

\section{References}

1 Mulder H, Nagorny CL, Lyssenko V, Groop L: Melatonin receptors in pancreatic islets: good morning to a novel type 2 diabetes gene. Diabetologia 2009:52:1240-1249.

2 Bouatia-Naji N, Bonnefond A, Cavalcanti-Proenca C, Sparso T, Holmkvist J, et al: A variant near mtnr1b is associated with increased fasting plasma glucose levels and type 2 diabetes risk. Nat Genet 2009;41:89-94.

3 Prokopenko I, Langenberg C, Florez JC, Saxena R, Soranzo N, et al: Variants in MTNR1B influence fasting glucose levels. Nat Genet 2009;41:77-81.

4 Staiger H, Machicao F, Schafer SA, Kirchhoff K, Kantartzis K, Guthoff M, Silbernagel G, Stefan N, Haring HU, Fritsche A: Polymorphisms within the novel type 2 diabetes risk locus MTNR1B determine beta-cell function. PLoS One 2008;3:e3962.

$\checkmark 5$ Kelliny C, Ekelund U, Andersen LB, Brage S, Loos RJ, Wareham NJ, Langenberg C: Common genetic determinants of glucose homeostasis in healthy children: the European Youth Heart Study. Diabetes 2009;58:2939-2945.

6 Langenberg C, Pascoe L, Mari A, Tura A, Laakso M, Frayling TM, Barroso I, Loos RJ, Wareham NJ, Walker M: Common genetic variation in the melatonin receptor $1 \mathrm{~b}$ gene (MTNR1B) is associated with decreased early-phase insulin response. Diabetologia 2009;52:1537-1542.

7 Lyssenko V, Nagorny CL, Erdos MR, Wierup N, Jonsson A, Spegel P, Bugliani M, Saxena R, Fex M, Pulizzi N, Isomaa B, Tuomi T, Nilsson P, Kuusisto J, Tuomilehto J, Boehnke M, Altshuler D, Sundler F, Eriksson JG, Jackson AU, Laakso M, Marchetti P, Watanabe RM, Mulder H, Groop L: Common variant in MTNR1B associated with increased risk of type 2 diabetes and impaired early insulin secretion. Nat Genet 2009:41:82-88.

8 Reiling E, van 't Riet E, Groenewoud MJ, Welschen LM, van Hove EC, Nijpels G, Maassen JA, Dekker JM, t Hart LM: Combined effects of single-nucleotide polymorphisms in GCK, GCKR, G6PC2 and MTNR1B on fasting plasma glucose and type 2 diabetes risk. Diabetologia 2009;52:1866-1870.
9 Sparso T, Bonnefond A, Andersson E, BouatiaNaji N, Holmkvist J, Wegner L, Grarup N, Gjesing AP, Banasik K, Cavalcanti-Proenca C, Marchand M, Vaxillaire M, Charpentier G, Jarvelin MR, Tichet J, Balkau B, Marre M, Levy-Marchal C, Faerch K, Borch-Johnsen K, Jorgensen T, Madsbad S, Poulsen P, Vaag A, Dina C, Hansen T, Pedersen O, Froguel P: G-allele of intronic rs10830963 in MTNR1B confers increased risk of impaired fasting glycemia and type 2 diabetes through an impaired glucose-stimulated insulin release: Studies involving 19,605 Europeans. Diabetes 2009:58:1450-1456.

10 Ronn T, Wen J, Yang Z, Lu B, Du Y, Groop L, Hu R, Ling C: A common variant in MTNR1B, encoding melatonin receptor $1 \mathrm{~b}$, is associated with type 2 diabetes and fasting plasma glucose in Han Chinese individuals. Diabetologia 2009;52:830-833.

11 Liu C, Wu Y, Li H, Qi Q, Langenberg C, Loos RJ, Lin X: MTNR1B rs10830963 is associated with fasting plasma glucose, HBA1C and impaired betacell function in Chinese Hans from Shanghai. BMC Med Genet 2010;11:59.

12 Tam CH, Ho JS, Wang Y, Lee HM, Lam VK, Germer S, Martin M, So WY, Ma RC, Chan JC, Ng MC: Common polymorphisms in MTNR1B, G6PC2 and GCK are associated with increased fasting plasma glucose and impaired beta-cell function in chinese subjects. PLoS One 2010;5:e11428.

$13 \mathrm{Hu}$ C, Zhang R, Wang C, Yu W, Lu J, Ma X, Wang J, Jiang F, Tang S, Bao Y, Xiang K, Jia W: Effects of GCK, GCKR, G6PC2 and MTNR1B variants on glucose metabolism and insulin secretion. PLoS One 2010;5:e11761.

14 Kan MY, Zhou DZ, Zhang D, Zhang Z, Chen Z, Yang YF, Guo XZ, Xu H, He L, Liu Y: Two susceptible diabetogenic variants near/in MTNR1B are associated with fasting plasma glucose in a Han Chinese cohort. Diabet Med 2010;27:598-602.

15 Li C, Shi Y, You L, Wang L, Chen ZJ: Association of rs10830963 and rs10830962 snps in the melatonin receptor (MTNR1B) gene among Han Chinese women with polycystic ovary syndrome. Mol Hum Reprod 2011;17:193-198.

16 Takeuchi F, Katsuya T, Chakrewarthy S, Yamamoto K, Fujioka A, Serizawa M, Fujisawa T, Nakashima E, Ohnaka K, Ikegami H, Sugiyama T, Nabika T, Kasturiratne A, Yamaguchi S, Kono S, Takayanagi R, Yamori Y, Kobayashi S, Ogihara T, de Silva A, Wickremasinghe R, Kato N: Common variants at the GCK, GCKR, G6PC2-ABCB11 and MTNR1B loci are associated with fasting glucose in two Asian populations. Diabetologia 2010;53:299-308
17 Kempf K, Rathmann W, Herder C: Impaired glucose regulation and type 2 diabetes in children and adolescents. Diabetes Metab Res Rev 2008;24:427437.

18 Wang HJ, Zhang H, Zhang SW, Pan YP, Ma J: Association of the common genetic variant upstream of INSIG2 gene with obesity related phenotypes in chinese children and adolescents. Biomed Environ Sci 2008;21:528-536.

19 Wang D, Ma J, Zhang S, Hinney A, Hebebrand J, Wang Y, Wang HJ: Association of the MC4R V103I polymorphism with obesity: a Chinese casecontrol study and meta-analysis in 55,195 individuals. Obesity (Silver Spring) 2010;18:573-579.

$20 \mathrm{Ji}$ CY: Report on childhood obesity in china (1) - body mass index reference for screening overweight and obesity in chinese school-age children. Biomed Environ Sci 2005;18:390-400.

21 Wallace TM, Levy JC, Matthews DR: Use and abuse of HOMA modeling. Diabetes Care 2004; 27:1487-1495.

22 WHO: Growth reference data for 5-19 years. Available at www.whoint/childgrowth/standards bmi_for_age/en/indexhtml, accessed: 2007.

23 Ye S, Dhillon S, Ke X, Collins AR, Day IN: An efficient procedure for genotyping single nucleotide polymorphisms. Nucleic Acids Res 2001;29:E8888 .

24 Genuth S, Alberti KG, Bennett P, Buse J, Defronzo R, Kahn R, Kitzmiller J, Knowler WC, Lebovitz H, Lernmark A, Nathan D, Palmer J, Rizza R, Saudek C, Shaw J, Steffes M, Stern M, Tuomilehto J, Zimmet P: Follow-up report on the diagnosis of diabetes mellitus. Diabetes Care 2003;26:3160 3167.

25 Morrison JA, Glueck CJ, Horn PS, Schreiber GB, Wang P: Pre-teen insulin resistance predicts weight gain, impaired fasting glucose, and type 2 diabetes at age 18-19 y: A 10-y prospective study of black and white girls. Am J Clin Nutr 2008;88:778-788.

26 Tirosh A, Shai I, Tekes-Manova D, Israeli E, Pereg D, Shochat T, Kochba I, Rudich A: Normal fasting plasma glucose levels and type 2 diabetes in young men. N Engl J Med 2005;353:1454-1462. 